\title{
ANATOMICAL VARIATIONS IN CONDUIT OF VERTEBRAL ARTERY IN ATLAS
}

\author{
Krishna Gopal ${ }^{1}$, Virendra Kumar², Vinod Kumar³, Jolly Agarwal ${ }^{4}$
}

\section{HOW TO CITE THIS ARTICLE:}

Krishna Gopal, Virendra Kumar, Vinod Kumar, Jolly Agarwal. "Anatomical variations in conduit of vertebral artery in atlas". Journal of Evolution of Medical and Dental Sciences 2013; Vol. 2, Issue 42, October 21; Page: 8030-8037.

ABSTRACT: BACKGROUND: The 1st cervical vertebra is named as atlas. It differs from all the other vertebrae in having no body and no spine. The atlas consists of two bulky lateral masses, connected to each other in front by a short anterior arch, and behind by a long curved posterior arch it thus forms a ring of bone. The posterior arch forms three-fifths of the atlantal ring. At the root of the arch the superior surface of posterior arch bears a wide groove for the vertebral artery, venous plexus and the $\mathrm{C} 1$ nerve immediately behind the lateral mass. In few cases this groove is converted into the completely or partially posterior/lateral vertebral artery foramen. AIM: This study was carried out to know the variations in posterior vertebral artery groove in atlas vertebra for clinical and surgical purpose. MATERIALS AND METHODS: The present study is based on the observation of the 300 macerated Human atlas vertebrae of North Indian present in the Anthropology Museum of Department of Anatomy, GSVM Medical College, Kanpur. The atlases were randomly selected the age and sex were not taken into consideration. RESULTS: We observed the complete posterior vertebral artery foramen in $8 \%$ specimen $(2.33 \%$ bilateral and $5.67 \%$ unilateral). In $3.33 \%$ it was found on left side and $2.33 \%$ on right side. Incidence of incomplete posterior vertebral artery foramen was observed in $9.33 \%$ (1.33\% bilateral and $8 \%$ unilateral). In 5\% it was found on left side and 3\% on right side. The bilateral presence of complete or incomplete lateral vertebral artery foramen was nil. The unilateral presence of complete or incomplete lateral vertebral artery foramen was found equal in frequency i.e. $0.67 \%$. The unilateral presence of complete lateral vertebral artery foramen on either side was found in $0.33 \%$ specimen whereas the incomplete lateral vertebral artery foramen was found only on left side $(0.67 \%)$. CONCLUSION: The presence of complete/incomplete posterior or lateral vertebral artery foramen may reduce the area of the space for the vertebral artery passing through the vertebral artery groove and may compress the vertebral artery which may result into various types of neurological symptomatology.

KEY WORDS: Atlas, Posterior arch, vertebral artery groove, vertebral artery.

INTRODUCTION: Vertebrae are named by regions. Cervical vertebrae of neck region can range from a single vertebra in amphibians to seven in most mammals. The $1^{\text {st }}$ cervical vertebra is named as atlas, because it supports the globe of the head. The name of the atlas is derived from a deity of Greek mythology called atlas. It differs from all the other vertebrae in having no body and this is due to the fact that the centrum of the atlas has been occupied with the centrum of the $2^{\text {nd }}$ cervical vertebra i.e. axis. In addition, it has no spine. The atlas consists of two bulky lateral masses, connected to each other in front by a short anterior arch, and behind by a long curved posterior arch it thus forms a ring of bone. The lateral mass carries the weight bearing articular facets. These facets serves to distinguish upper from lower surfaces. In contrast to the deep concavity of the upper kidney shaped surfaces the lower facets are circular and flat. The lateral mass is projected laterally 
into the transverse process, which is perforated by the transverse foramen. Gardner $\mathrm{E}^{1}$ and Davies $\mathrm{F}^{2}$ suggested that the posterior arch of atlas vertebra which corresponds to the laminae of other vertebrae, presents a wide groove for the vertebral artery on its upper surface. The first cervical nerve is also present in this groove. A spicule of bone sometimes projects backwards from the lateral mass and may convert the groove into a foramen for the vertebral artery and first cervical nerve. Davies $\mathrm{F}^{2}$ also explained that behind the groove, on each side, the upper border of the posterior arch gives attachment to the posterior atlanto - occipital membrane; its lower border gives attachment to the highest pair of ligament flava. Last ${ }^{3}$ observed that the free border of the posterior atlantooccipital membrane, arching over the artery and nerve is sometimes ossified and converted the groove for the vertebral artery; into a foramen. The vertebral artery arises from the upper and posterior part of the first part of the subclavian artery. It ascends through the transverse foramina of the upper six cervical vertebrae, with a large branch derived from the cervico-thoracic cervical ganglion and a plexus of vein. It lies in front of the ventral rami of cervical nerve (C2-C6) and pursues an almost vertical course as far as the transverse process of the axis, through which it runs upwards and laterally to the transverse foramen of atlas. After passing through the transverse foramen it runs on the medial side and curves backwards behind the lateral mass of atlas, the ventral ramus of the first cervical nerve being on its medial side; It then lies in the groove on the upper surface of the posterior arch of atlas and enters the Vertebral canal by passing below the lower, arched border of the posterior atlanto occipital membrane. Susan Standring 4 suggested that the movements of atlanto-occipital joints allow mainly for flexion and extension, which has a total range of about 15 degree, and the lateral flexion on either side, has not been measured in living subjects. In the event of presence of posterior or lateral vertebral artery foramen whether it is complete or incomplete may be unilateral or bilateral, the vertebral artery becomes unprotective and exposed to be pressed on either sided lateral flexion which may result into various types of neurological symptomatology depending upon the severity of pressure hence a clinician needs to pay the special attention to keep these variations in mind to explore the cause of neurological symptoms specially when the symptomatology enhances on lateral flexion.

MATERIALS AND METHODS: The present study is based on the observation of 300 atlas Vertebrae, randomly selected from stock of vertebrae belonging to north India present in the Anthropology museum of Department of Anatomy, GSVM Medical College, Kanpur. The macerated atlas vertebrae were randomly selected. The age and sex of the vertebrae were not taken into consideration. The vertebrae were cleaned properly and examined non metric variants.

The posterior arch of atlas and vertebral artery grooves over it was observed carefully.

1. The vertebral artery groove was examined for any bony outgrowth or spicule over it and it was noted that whether these bony growth forms a complete or incomplete foramen over the vertebral artery groove and whether these conversions are unilateral or bilateral.

2. It was also found that in some atlas vertebrae a bony spicule arises from a posterior side of superior articular surface or the lateral side of superior articular surface.

3. The bony outgrowth or spicule, bridges partially or completely over the vertebral artery groove and converted it into posterior or lateral incomplete/complete vertebral artery foramen. 


\section{RESULT:}

1. The study revealed that 24 atlases out of 300 were having the complete posterior vertebral artery foramen (8\%). In which 17 atlases showed unilateral presence of complete posterior vertebral artery foramen (5.67\%). Out of these 17 atlases the complete posterior vertebral artery foramen was found in 10 specimens on left side (3.33\%), (fig. 1) and 7 on right side $(2.33 \%)$, fig. (2). Seven atlases shown the bilateral presence of complete posterior vertebral artery foramen (2.33\%), fig. (3). Refer to table number (1).

2. Twenty eight atlases showed the presence of incomplete posterior vertebral artery foramen out of 300 (9.3\%). In which the unilateral presence of incomplete posterior vertebral artery foramen was seen in 24 atlases (8.0\%) and out of these the incomplete posterior vertebral artery foramen was seen 15 on left side (5.0\%), fig. (4) and 9 on right side (3.0\%), fig. (5) and 4 atlases shown the bilateral presence of incomplete posterior vertebral artery foramen (1.33\%), fig. (6). Refer to table number (2).

3. Our study revealed that the presence of incomplete posterior vertebral artery foramen was more as compare to complete posterior vertebral artery foramen i.e. 9.3\%: 8.0\%.

4. The unilateral presence of incomplete posterior vertebral artery foramen was more as compare to complete posterior vertebral artery foramen i.e. (8.0\%: 5.67\%).

5. The unilateral presence on left side of incomplete posterior vertebral artery foramen (5\%) was found more as compare to the complete posterior vertebral artery foramen $(3.33 \%)$.

6. The unilateral presence on right side of incomplete posterior vertebral artery foramen (3\%) were found more as compare to complete posterior vertebral artery foramen $(2.33 \%)$.

7. Therefore the frequency of left sided incomplete posterior vertebral artery foramen and the complete posterior vertebral artery foramen is more as compare to right side.

8. The bilateral presences of complete posterior vertebral artery foramen were more as compare to the incomplete posterior vertebral artery foramen (2.33\%:1.33\%). Refer to table number (1\&2).

9. Our study revealed that the bilateral presence of complete or incomplete lateral vertebral artery foramen was nil $(0.0 \%)$. However the unilateral presence of complete lateral vertebral artery foramen and incomplete lateral vertebral artery foramen was found equal in frequency i.e. $0.67 \%$. The presence of complete lateral vertebral artery foramen was found equally on both sides $(0.33 \%$ on left and $0.33 \%$ on right) [table number (3), fig. - 7 \& 8], whereas the presence of incomplete lateral vertebral artery foramen was found on left side only i.e. $0.67 \%$ [table number (4), fig. - 9].

DISCUSSION: Our study revealed 8\% presence of complete posterior vertebral artery foramen Poipier ${ }^{5}$ also reported the same percentage of presence of complete posterior vertebral artery. Taitz and Nathan ${ }^{6}$ and Loth-Niemirycz ${ }^{7}$ reported $7.9 \%$ and $7.4 \%$ presence of complete posterior vertebral artery respectively, which is almost same percentage as our study revealed.

As for as percentage of presence of complete posterior vertebral artery foramen is concerned, J.wysocki ${ }^{8}$ has reported the range of presence as 1.14 to $29.2 \%$ on the basis of the work of other workers but he has witnessed $13.8 \%$ presence of complete posterior vertebral artery foramen. The other workers like Cacciola F ${ }^{9}$, et al, George P. et al ${ }^{10}$, Cakmak et al ${ }^{11}$ reported 10\%, $10.23 \%$ and $11.7 \%$ presence of the complete posterior vertebral artery foramen respectively which 
are very near to our finding. Whereas Dubreuil-Chambardel ${ }^{12}$ and Lamberthy and Zivancovic ${ }^{13}$ reported the higher percentage as 30\% and 15\% respectively and Malhotra et al have reported as low percentage of presence of complete posterior vertebral artery foramen as $5.14 \%$, which are almost in the range of presence of the complete posterior vertebral artery foramen as already reported by J.wysocki et al ${ }^{8}$. Our study also revealed the bilateral presence of complete posterior vertebral artery foramen in $2.33 \%$ of specimen. Manjunath et al ${ }^{14}$ and Lamberthy and Zivancovic ${ }^{13}$ reported $1.65 \%$ and $3.33 \%$ presence of bilateral complete posterior vertebral artery foramen which is almost near to our observation whereas Radojevic and Negovanovic 15 reported the presence of bilateral complete posterior vertebral artery foramen as high as 7\%. Malhotra et al ${ }^{16}$ reported it as low as $1.42 \%$ of specimens. Our study also revealed the bilateral presence of complete posterior vertebral artery foramen in $2.33 \%$ of the specimen that clearly showed that our finding is within the range of the presence of bilateral complete posterior vertebral artery foramen reported by the other workers.

Our study revealed the unilateral presence of complete posterior vertebral artery foramen as $5.67 \%$ in which $3.33 \%$ was on left side and $2.33 \%$ was on right side. Malhotra et al ${ }^{16}$ reported unilateral presence of complete posterior vertebral artery foramen as $3.71 \%$ (1.42\% on right and $0.28 \%$ on left side), these reports are very near to our observation.

Our study revealed $9.3 \%$ presence of incomplete posterior vertebral artery foramen. Radojevic and Negovanovic ${ }^{15}$ reported $2 \%$, Lamberthy and Zivancovic ${ }^{13}$ reported $21.66 \%$ presence, Malhotra et al ${ }^{16}$ in $7.71 \%$, Taiz C et al ${ }^{6}$ in $25.90 \%$, Cakmak ${ }^{11}$ in $3.3 \%$, and George $\mathrm{P}$ et al ${ }^{10}$ in $24.43 \%$ and that showed the presence of incomplete posterior vertebral artery foramen varies from $2.0 \%$ to $25.90 \%$ and our observation is within the range. Our study revealed the bilateral presence of incomplete posterior vertebral artery foramen was found $1.33 \%$ Malhotra et al ${ }^{16}$ reported it to be $0.85 \%$ which is also very near to our study. Our study revealed the unilateral presence of incomplete posterior vertebral artery foramen was found in $8 \%$ of specimen (5\% on left and $3 \%$ on right side). Malhotra et al $^{16}$ reported $6.85 \%$ presence of unilateral incomplete posterior vertebral artery foramen (3.71\% on left and $3.14 \%$ on right side). Our study revealed that the presence of incomplete posterior vertebral artery foramen was more as compare to complete posterior vertebral artery foramen i.e. 9.3\%: 8.0\%. The unilateral presence of incomplete posterior vertebral artery foramen was more as compare to complete posterior vertebral artery foramen i.e. $8.0 \%$ : 5.67\%. The unilateral presence on left side of incomplete posterior vertebral artery foramen (5\%) was found more as compare to the left side of complete posterior vertebral artery foramen $(3.33 \%)$. The unilateral presence on right side of incomplete posterior vertebral artery foramen (3\%) were found more as compare to right side of complete posterior vertebral artery foramen $(2.33 \%]$. Therefore the frequency of left sided incomplete posterior vertebral artery foramen and the complete posterior vertebral artery foramen is more as compare to right side.

The bilateral presence of complete posterior vertebral artery foramen was more as compare to the incomplete posterior vertebral artery foramen (2.33\%:1.33\%) [Refer to table number (1\&2)]. These finding cannot be compared with the other workers as they have not thrown the light on these aspects. Breathnach ${ }^{17}$ and Hasan $M$ et al ${ }^{18}$ described the lateral vertebral artery foramen. Hasan $M$ et $\mathrm{al}^{18}$ also explained that the lateral vertebral artery foramen on the atlas is of normal occurrence in lower animals and reported it in $1.14 \%$ of specimen. Our study revealed the bilateral presence of complete or incomplete lateral vertebral artery foramen was nil. Our study revealed that the 
unilateral presence of complete or incomplete lateral vertebral artery foramen was found equal in frequency i.e. $0.67 \%$. Malhotra et al ${ }^{16}$ reported this frequency as $0.85 \%$. He has also reported that the frequency of complete and incomplete lateral vertebral artery foramen were $0.57 \%$ and $0.28 \%$ respectively. Our study revealed the unilateral presence of complete lateral vertebral artery foramen on either side in $0.33 \%$ whereas the incomplete lateral vertebral artery foramen was found on left side only in $0.67 \%$. Our observation is close to that of Malhotra et al 16 .

\begin{tabular}{|c|c|c|c|c|c|c|c|c|}
\hline \multirow{2}{*}{ Specimen } & \multirow{2}{*}{ Incidence } & \multicolumn{5}{|c|}{$\begin{array}{c}\text { Vertebral artery foramen } \\
\text { (No. of Atlases) }\end{array}$} & \multirow{2}{*}{$\begin{array}{l}\text { Total (Unilateral } \\
\text { +bilateral) }\end{array}$} & \multirow{2}{*}{$\%$} \\
\hline & & Left & $\%$ & Right & $\%$ & $\begin{array}{c}\text { Total } \\
\text { (left + Right })\end{array}$ & & \\
\hline \multirow{2}{*}{ Atlas } & Unilateral & 10 & 3.33 & 7 & 2.33 & $\begin{array}{c}17 \\
(5.67 \%)\end{array}$ & \multirow{2}{*}{24} & \multirow{2}{*}{8} \\
\hline & Bilateral & \multicolumn{5}{|c|}{$\begin{array}{c}7 \\
(2.33)\end{array}$} & & \\
\hline
\end{tabular}

\begin{tabular}{|c|c|c|c|c|c|c|c|c|}
\hline \multirow{2}{*}{ Specimen } & \multirow{2}{*}{ Incidence } & \multicolumn{5}{|c|}{$\begin{array}{c}\text { Vertebral artery foramen } \\
\text { (No. of Atlases) }\end{array}$} & \multirow{2}{*}{ Total (Unilateral + bilateral) } & \multirow{2}{*}{$\%$} \\
\hline & & Left & $\%$ & Right & $\%$ & $\begin{array}{c}\text { Total } \\
\text { (left + Right })\end{array}$ & & \\
\hline \multirow{2}{*}{ Atlas } & Unilateral & 15 & 5 & 9 & 3 & $\begin{array}{c}24 \\
(8.0 \%)\end{array}$ & \multirow{2}{*}{28} & \multirow{2}{*}{9.3} \\
\hline & Bilateral & \multicolumn{5}{|c|}{$\begin{array}{c}4 \\
(1.33)\end{array}$} & & \\
\hline
\end{tabular}

\begin{tabular}{|c|c|c|c|c|c|c|c|}
\hline \multirow[t]{2}{*}{ Specimen } & \multirow[t]{2}{*}{ Incidence } & \multicolumn{4}{|c|}{$\begin{array}{c}\text { Vertebral artery foramen } \\
\text { (No. of Atlases) }\end{array}$} & \multirow[t]{2}{*}{ Total (Unilateral + Bilateral)) } & \multirow[t]{2}{*}{$\%$} \\
\hline & & Left & $\%$ & Right & $\%$ & & \\
\hline \multirow{2}{*}{ Atlas } & Unilateral & 1 & 0.33 & 1 & 0.33 & \multirow{2}{*}{2} & \multirow{2}{*}{0.67} \\
\hline & Bilateral & & & 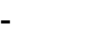 & & & \\
\hline
\end{tabular}

\begin{tabular}{|c|c|c|c|c|c|c|c|}
\hline \multirow[t]{2}{*}{ Specimen } & \multirow[t]{2}{*}{ Incidence } & \multicolumn{4}{|c|}{$\begin{array}{l}\text { Vertebral artery foramen } \\
\text { (No. of Atlases) }\end{array}$} & \multirow[t]{2}{*}{ Total (Unilateral+ Bilateral) } & \multirow[t]{2}{*}{$\%$} \\
\hline & & Left & $\%$ & Right & $\%$ & & \\
\hline \multirow{2}{*}{ Atlas } & Unilateral & 2 & 0.67 & - & - & \multirow{2}{*}{2} & \multirow{2}{*}{0.67} \\
\hline & Bilateral & \multicolumn{4}{|c|}{-} & & \\
\hline
\end{tabular}




\section{ORIGINAL ARTICLE}

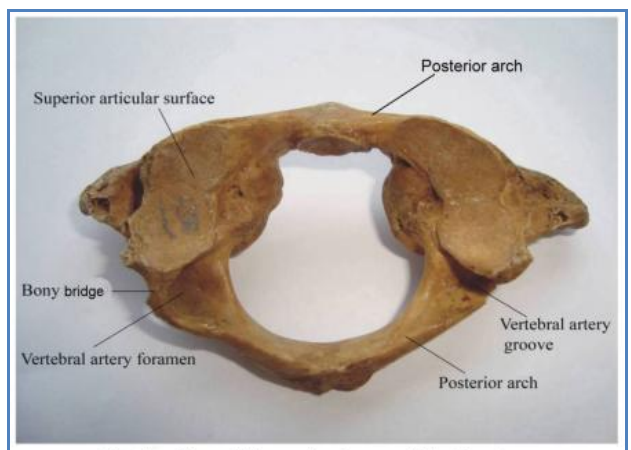

Fig. 1: Complete posterior vertebral artery foramen (left side)
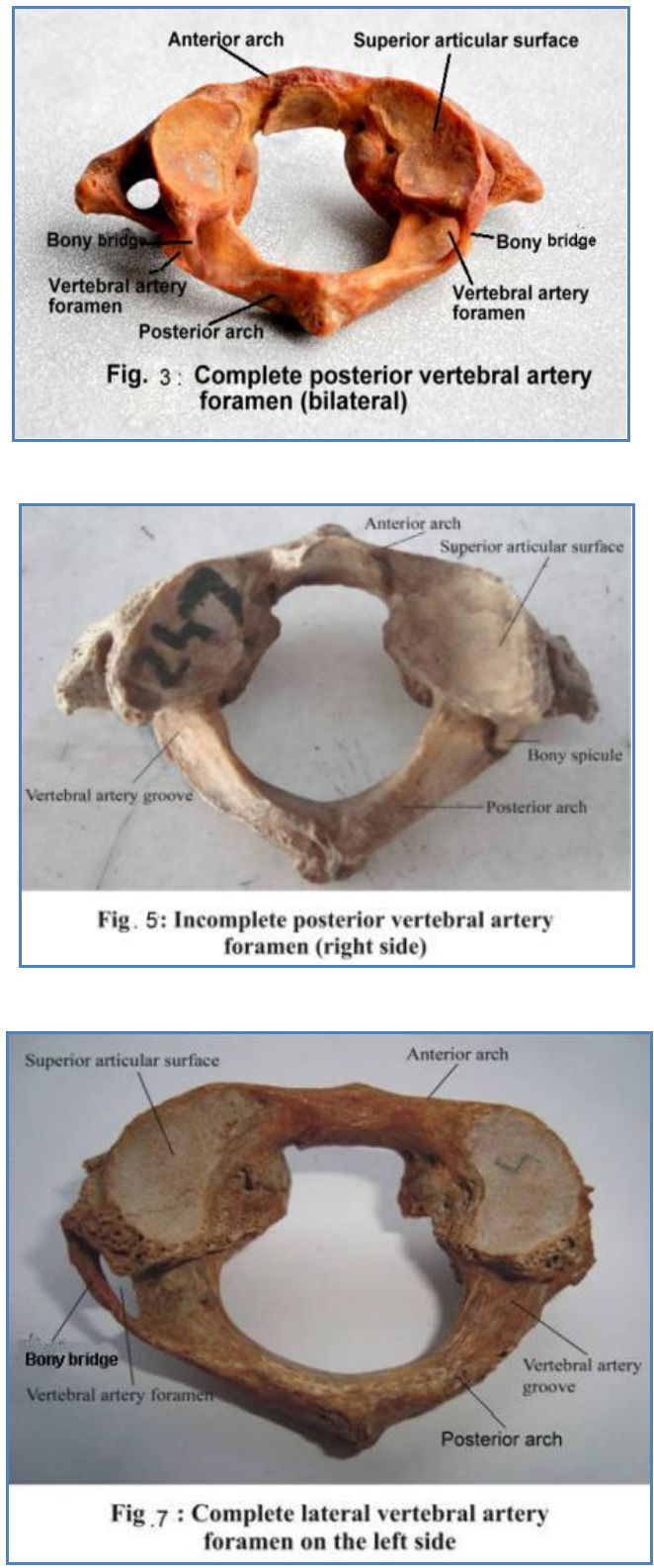
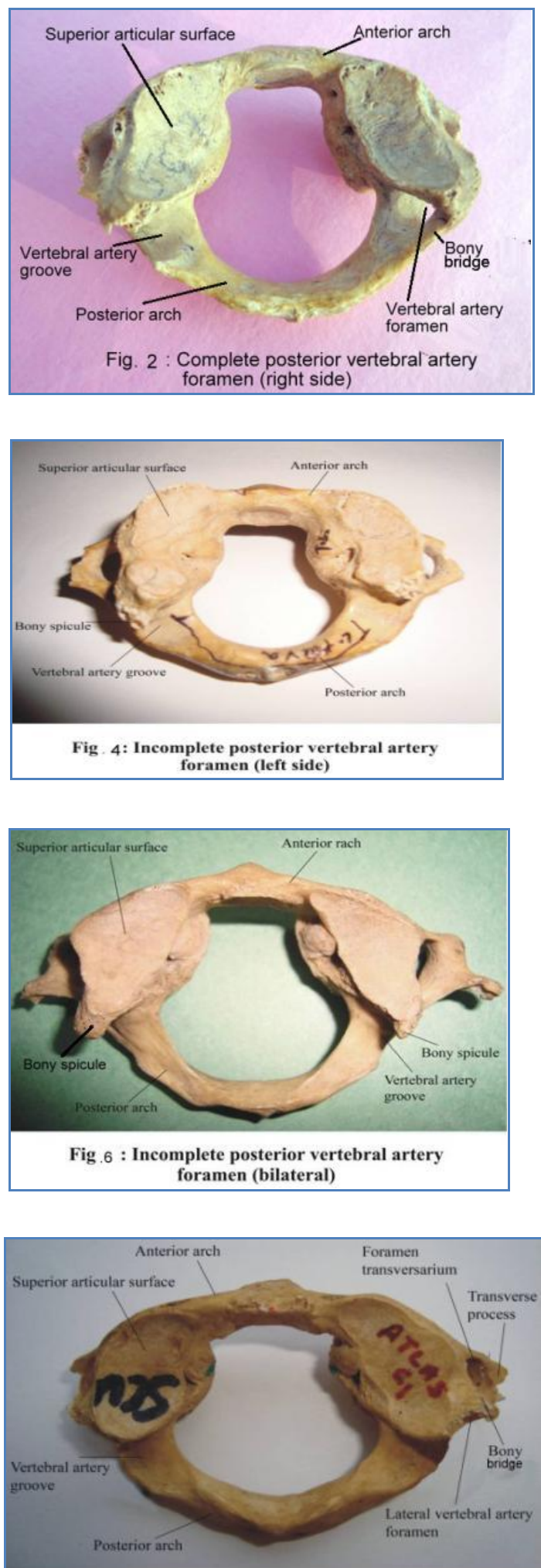

Fig. 8 :Complete lateral vertebral artery foramen on the right side 


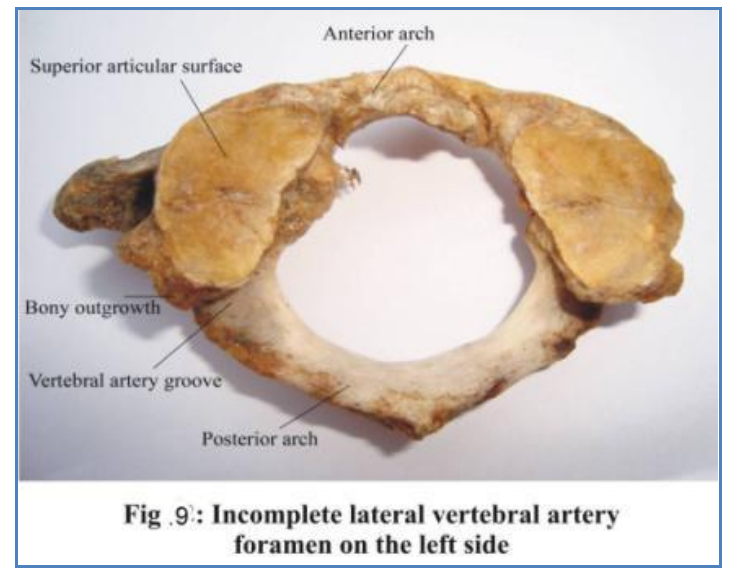

CONCLUSION: In the study of 300 macerated human atlas vertebrae we observed the vertebral artery groove for its conversion into the foramen. We observed the complete posterior vertebral artery foramen in $8 \%$ specimen. In $2.33 \%$ it was found bilaterally and $5.67 \%$ unilaterally. In $3.33 \%$ it was found on left side and $2.33 \%$ on right side. In $9.33 \%$ of specimen incomplete posterior vertebral artery foramen was observed. It was found more on the left side than that of right side. In $0.67 \%$ of specimen complete lateral vertebral artery foramen was observed. The incomplete lateral vertebral artery foramen also observed in $0.67 \%$ of specimen. These variations can also be easily confused with enlarged atlas posterior arch. Surgeons should review cervical spine tomography images in order to check the presence of posterior vertebral artery foramen and to outline medial and lateral boundaries for surgical exposure to achieve safe procedure, preventing injuries to the vertebral artery and the related nerves.

The vertebral artery is vulnerable to compression in its course between foramen transversarium and the foramen magnum during extreme rotation of the head and neck. This situation may be aggravated by the presence of posterior or lateral bridges of atlas and result in compromised blood flow. The presence of bony bridging should also be taken into account by the orthopedic surgeons during a surgical manipulation of the cervical spine.

\section{REFERENCES:}

1. Gardner E., Gray D.J. and O' Rahilly R: In Anatomy. A regional study of human structure. London, W.B. Saunders Company Philadelphia, 1960 pp. 638.

2. Davies F. and Davies D.V: Osteology of cervical vertebrae. Gray's Anatomy. 33 ${ }^{\text {rd }}$ Ed Longmans, Green Co. Ltd. 1962, pp. 254.

3. Last R.J: In Anatomy Regional and applied. 4th Ed. J and A Churchill Ltd. London. 1966 pp. 632.

4. Susan Standring et al: Joints. Gray's Anatomy, the anatomical basis of clinical practice, $40^{\text {th }}$ Ed. Elsevier, 2008. pp. 734.

5. Poipier P. Traite d' anatomic humaine; quoted by Acta Anatomica 1911; 85: 113 - 122.

6. Taitz C, Nathan H.: Some observation on the posterior and lateral bridge of the atlas. Acta Anat (Basel). 1986; 127 (3): 212 - 217.

7. Loth-Niemirycz J: Etudes anatomiques surle canal transversaire quoted by Acta Anatomica 1916; 85: $113-122$. 
8. J. Wysocki, M. Bubrowski, J. Reymond, J. Kwialkowski: Anatomical variants of cervical Vertebrae and the first thoracic vertebra in man. Folio Morphol. 2003; 62(4): 357 - 636

9. Cacciola F, Phalke V, Goel A.: Vertebral artery in relationship to C1-C2 vertebrae; An anatomical study: neural India 2004; 52: 178 - 184.

10. George P, basilios Papaziogas, Christos Tsonidis and G. Kapetanos: Gross morphology of the bridges over the vertebral artery groove on the atlas. Journal of Surgical and radiological Anatomy 2005; 27(2): 129 - 136.

11. Cakmak O, Gurdal E., E. Kinci G, Yildiz E, Cavdar S: Arcuate Foramen and its clinical significant. Saudi Med J 2005; 62: 1409 - 1413.

12. Dubreuil-Chambardel, L. L'atlas (Vigot, Paris) Quoted by Acta Anatomica. 1921; 85: 113 122.

13. Lamberthy B. G.H. and Zivancovic S: The retro articular vertebral artery ring of the atlas and its significance. Acta Anatomica; 1973; 85: 113 - 122.

14. Manjunath KY: Posterior bridging of the atlas vertebra in South Indians. J Medical Science 2001; 55: 488 - 490.

15. Radojevic S, Negovanovic P.L: La gouttiere et les anneaux Osseus de I' artere vertebrale de I'atlas Acta Anatomica 1963; 55: 186 - 196.

16. Malhotra V.K., Tewari S.P and Bajpai R.N: Study of vertebral artery foramen on atlas vertebra. J. Anat. Soc. India.1979; vol. 28(2).

17. Breathnach, A.S. Vertebral column: Frazer's Anatomy of the human skeleton $5^{\text {th }}$ Ed J and A. Churchill Ltd., London. 1958. pp. 25.

18. Hasan M, Shukla S, Siddiqui MS, Singh D: posterolateral tunnels and ponticuli in human atlas vertebrae J Anat. 2001; 199: 339 - 43.

\section{AUTHORS:}

1. Krishna Gopal

2. Virendra Kumar

3. Vinod Kumar

4. Jolly Agarwal

\section{PARTICULARS OF CONTRIBUTORS:}

1. Assistant Professor, Department of Anatomy, Shri Ram Murti Smarak Institute of Medical Sciences, Bareilly.

2. Professor \& Head, Department of Anatomy, Shri Ram Murti Smarak Institute of Medical Sciences, Bareilly.

3. Professor \& Head, Department of Anatomy, Government Medical College, Jalaun (Orai).
4. PG Student, Department of Anatomy, Shri Ram Murti Smarak Institute of Medical Sciences, Bareilly.

\section{NAME ADRRESS EMAIL ID OF THE CORRESPONDING AUTHOR:}

Dr. Krishna Gopal, Department of Anatomy, Shri Ram Murti Smarak Institute of Medic al Sciences,

Nainital Road, Bhijipura, Bareilly - 243202 (U.P.)

Email - drkrish2007@gmail.com

Date of Submission: 01/10/2013.

Date of Peer Review: 03/10/2013.

Date of Acceptance: 07/10/2013.

Date of Publishing: 15/10/2013 